\title{
INCIDENCE OF VASOVAGAL REACTION AMONG THE BLOOD DONORS ATTENDING AT TRANSFUSION MEDICINE DEPARTMENT OF DHAKA MEDICAL COLLEGE HOSPITAL
}

\author{
CHOWDHURY FS ${ }^{1}$, SIDDIQUI MAE ${ }^{2}$, RAHMAN KGM ${ }^{3}$, BEGUM HA ${ }^{4}$, BEGUM HA ${ }^{5}$, HOQUE $\mathrm{MM}^{6}$, NASREEN Z
}

\begin{abstract}
:
Introduction: Without blood there may be no blood transfusion. Without donors there may not any blood. During vasovagal reaction there is chance of accidental fall and injury to blood donor. So improving the safety of the blood donation experience will reduce the donor injuries and increase the blood donation, donation frequency and donor satisfaction.

Objective: This study was done to find out the incidence of blood donor reaction-vasovagal reactions among the blood donors attending at transfusion medicine department of Dhaka Medical College Hospital and to improve the donor's safety.

Methodology: This study was done at Transfusion Medicine Department of Dhaka Medical College Hospital in the period between January 2010 to December 2010. Total 21815 donors of 18 to 55 years of both sexes were selected after reviewing the questionnaire, physical and medical examination and written consent. Donors were observed for 30 minutes after donation. The needle site was covered with a bandage and the donor was directed to keep the bandage on for several hours.

Result: In this study, out of 21815 donors 163(8.7\%) developed reaction. In163 reactions, 72(44.18\%) were in male and 91 (55.82\%) were in female donors. Within 20179 male donors, adverse reactions occurred in 72 (0.35\%) and within 1636 female donors, adverse reactions occurred in 91 (5.56\%) The symptoms were agitation 23 (14.12\%), pallor 31 (19.02\%), sweating 29 (17.79\%), nausea 21 (12.88\%), vomiting 38 (23.21\%), cold feeling 12(7.36\%), loss of consciousness 9(5.52\%), i.e. severe reactions were 9(5.53\%) and mild to moderate reactions were 154 (94.47\%). Among the reactions 127 (0.89\%) occurred in new donors, 32 (0.49\%) occurred in occasional donors and 4 (0.37\%) in periodic donors.

Conclusion: Vasovagal reactions are more common in female and new donors.
\end{abstract}

Key words: Blood donor, vasovagal reaction.

\section{Introduction:}

Blood transfusion differs from all other medical activities and therapy that it concerns not only doctors and patient but also blood donors. Without blood there may be no blood transfusion. Without donors there may not any blood. Careful donor selection contributes vitally to the safety of both donor and recipient. Work of blood transfusion starts with collection of blood. Blood donation is not completely free from risk. The risks of donation are less when donors are fit and well. Blood must be collected under the responsibilities of a physician. Any adult individual who is in good health, free from any recent serious infection, between 18-55 years, haemoglobin above $12 \mathrm{gm} / \mathrm{dl}$, weight above $50 \mathrm{~kg}$, blood pressure above 100/60 mm Hg and below 200/100 mm Hg, pulse 60-100/ minute, temperature normal can donate blood after every four months ${ }^{1}$. Most donor tolerate giving blood very well but occasionally a donor will have an adverse reaction to the donation. Most reactions are vasovagal reactions. The reactions may be the result of psychological influences caused by sight of blood, watching others to give blood, excitement, fear, apprehension or for unexplained reasons. They may be a neurophysiologic response to the donation ${ }^{2}$. Reactions are mild, moderate, and

1. Asst. Prof, Transfusion Medicine, National Institute of Kidney Diseases \& Urology, Dhaka.

2. Consultant, Cardiology, NITOR.

3. Assoc. Prof. Forensic Medicine, Dhaka Medical College, Dhaka

4. Professor BTC, Dhaka Medical College, Dhaka

5. Associate Professor, BTC, Dhaka Medical College, Dhaka

6. Assistant Professor, BTC, Dhaka Medical College, Dhaka

7. MO, BTC, , Dhaka Medical College Hospital, Dhaka.

Bangladesh J Medicine 2011; 22 : 47-50 
severe. Mild reactions are signs of shock without loss of consciousness i.e. anxiety, nervousness, nausea, vomiting, feeling cold, pallor, sweating, rapid and thready pulse, hyperventilation. Moderate reactions are progression of mild reactions with loss of consciousness. Mild and moderate reactions are managed by stopping the donations, loosening the clothes, clearing the airways, rebreathing in a paper bag, raising the feet end (Trendelenburg position), cold sponging over forehead or back of the neck, checking pulse, blood pressure, temperature, administering oxygen. Severe reactions are signs of shock with convulsion and vasovagal syncope. Severe reactions are managed as before after removing from donor couch to prevent injury ${ }^{3}$.

\section{Methodology:}

Donors were selected after information and counseling about fulfilling the criteria. Donors were given a donor questionnaire that included several basic health and sensitive lifestyle questions required to protect both the donor and patient. Doctors reviewed the questionnaire and performed a health screening examination where pulse, blood pressure, temperature, haemoglobin, weight were checked. Donors of both sexes, between 18-55 years, Hb-more than $12 \mathrm{~g} / \mathrm{dl}$, weight above $50 \mathrm{~kg}$, who is in good physical and mental health, free from any infection (malaria, hepatitis, typhoid, tuberculosis, syphilis) were included. Donors with history of allergy, hypertension (with or without medication), diabetes (taking insulin), surgery (within 6 months), tooth extraction (within 6 weeks), immunization (live vaccine within 4 weeks), blood donation (within 4 months), receiving blood or blood component (within 12 months), delivery, lactation, menstruation, travelling, drug addiction were excluded. After physical examination, informed written consent was taken. With all aseptic precaution about $450 \mathrm{ml}$ blood was collected in blood collecting bag with anticoagulant taking about 15 minutes ${ }^{4}$.Donors were observed for 30 minutes after donation. The donors were given light refreshments to help the donor recover. The needle site was covered with a bandage and the donor was directed to keep the bandage on for several hours ${ }^{5}$.

\section{Results:}

Results are given in tables.

Table I

Distribution of donors by sex $(n=21815)$

\begin{tabular}{lcc}
\hline Sex of donors & No of donors & Percentage \\
\hline Male & 20179 & 92.5 \\
Female & 1636 & 7.5 \\
\hline
\end{tabular}

Table II

Distribution by types of donors depending on frequency of donation $(n=21815)$

\begin{tabular}{lcc}
\hline Types of donors & No of donors & $\%$ \\
\hline Periodic & 1091 & 5.01 \\
Occasional & 6544 & 29.99 \\
New & 14180 & 65.00 \\
\hline
\end{tabular}

Table-III

Distribution by reaction $(n=21815)$

\begin{tabular}{lcc}
\hline Reaction occurred or not & No of donors & $\%$ \\
\hline Reaction & 163 & 8.74 \\
No reaction & 21652 & 91.26 \\
\hline
\end{tabular}

Table-IV

Distribution by symptoms $(n=163)$

\begin{tabular}{lcc}
\hline Symptoms & No & $\%$ \\
\hline Agitation & 23 & 14.12 \\
Pallor & 31 & 19.02 \\
Sweating & 29 & 17.79 \\
Nausea & 21 & 12.88 \\
Vomiting & 38 & 23.21 \\
Cold feeling & 12 & 7.36 \\
Loss of consciousness & 09 & 5.52 \\
\hline
\end{tabular}

Table-V

Distribution by severity of adverse reactions ( $n=163)$

\begin{tabular}{lcc}
\hline Severity of reaction & No & $\%$ \\
\hline Mild to moderate & 154 & 94.47 \\
Severe & 09 & 5.53 \\
\hline
\end{tabular}

Table-VI

Distribution of adverse reactions by sex of donors $(n=21815)$

\begin{tabular}{lccr}
\hline Sex & No of reaction & No of donor & $\%$ \\
\hline Male & 72 & 20179 & 0.35 \\
Female & 91 & 1636 & 5.56 \\
\hline
\end{tabular}

Table-VII

Distribution of reactions by types of donor depending on frequency of donation

\begin{tabular}{lccc}
\hline Types of donors & $\begin{array}{c}\text { No of } \\
\text { reactions }\end{array}$ & $\begin{array}{c}\text { No of } \\
\text { donor }\end{array}$ & $\%$ \\
\hline Periodic & 4 & 1091 & 0.37 \\
Occasional & 32 & 6544 & 0.49 \\
New & 127 & 14180 & 0.89 \\
\hline
\end{tabular}




\section{Discussion:}

In this study, total donors were 21815 , in which male were 20179 (92.5\%) and female were 1636 (7.5\%). Out of 21815 donors 163 (8.7\%) developed vasovagal reactions. In 163 reactions, $72(44.18 \%)$ were in male and 91 (55.82\%) were in female donors. Within 20179 male donors, adverse reactions occurred in $72(0.35 \%)$ and within 1636 female donors, adverse reactions occurred in 91 (5.56\%) It indicates that reactions are higher in female. The symptoms were agitation 23 (14.12\%), pallor 31 (19.02\%), sweating 29 (17.79\%), nausea 21 (12.88\%), vomiting 38 (23.21\%), cold feeling $12(7.36 \%)$,loss of consciousness 9 (5.52\%), i.e. severe reactions were $9(5.53 \%)$ and mild to moderate reactions were $154(94.47 \%)$. Among the reactions $127(0.49 \%)$ occurred in new donors, 32 $(0.49 \%)$ occurred in occasional donors and $4(0.37)$ in periodic donors. Now the conclusion is that vasovagal reactions are more common in female and new donors. One study showed that $2 \%$ of donors had an adverse reaction to donation ${ }^{6}$. Most of these reactions are minor. Studies have demonstrated that approximately $3 \%$ to $10 \%$ of blood donors will experience an adverse reaction or injury after the donation ${ }^{7}$. In one study records of 422,231 allogenic whole blood donations over a 9-month period and assessed for pre-faint and faint reactions. They found a total of 6,049 adverse events; a rate of $1.43 \%$. Of this total, the percent of mild, moderate or severe reactions was $63 \%, 29 \%$ and $8 \%$ respectively. Predictors of these reactions were age, sex, blood volume, blood pressure, pulse, and body mass index. The strongest predictors of a reaction were donor blood volume of less than 3500 $\mathrm{ml}$, age, and first time donor status ${ }^{8}$. In one study the prevalence of moderate to severe reactions was 41 in 10,000 donations; $24 \%$ of these reactions were delayed, and $12 \%$ occurred offsite. Delayed reactions were associated with female gender. Low estimated blood volume, youth, and first-time donor status were major risk factors for immediate and delayed reactions. Women were more likely than men to report delayed reactions ${ }^{9}$. Adverse reactions recorded in the American Red Cross donor hemovigilance program in 2006, adverse reactions occurred at a rate of 7.4, 5.2, and 3.3 per 10,000 collections for whole blood, apheresis platelet, and 2-unit automated red cells ${ }^{10}$. The donor reaction rate was 12.0 percent $(870 /$ 7274). Female donors overall had a higher donor reaction rate than male donors $(16.7 \%$ vs. $7.3 \%)$. A model suggested that a change in the blood-unit volume from 450 to $500 \mathrm{ml}$ would increase donor reaction rates by 18 percent in either female or male donors, whereas a reduction in the blood-unit volume from 500 to $400 \mathrm{ml}$ would decrease donor reaction rates by 29 and 27 percent in female and male donors, respectively ${ }^{11}$. Donors who developed delayed faint should be indefinitely deferred from blood donation ${ }^{12}$.Syncopal reactions most commonly occur at the refreshment table where preventive safety measure against trauma could be applied ${ }^{13}$.

\section{Conclusion:}

Reactions can be reduced by proper donor selection. All donors should be observed for at least $15 \mathrm{~min}$ after donation and should be questioned about their occupation. Donors in whom fainting would be especially hazardous to themselves or to others (pilot, surgeons, bus drivers) should refrain from work or potentially dangerous hobbies for up to $12 \mathrm{hrs}$ after giving blood.

\section{Acknowledgement:}

Special thanks to all medical and non-medical person of the department for their service, work, and cordial help for the study.

\section{Conflicts of interest: None}

\section{References}

1. Rahman M, Essential Book on Transfusion medicin, $1^{\text {st }}$ edt,2007,p:40-50.

2. Denise M.Harmen, Modern Blood Banking and Transfusion Practice, $3^{\text {rd }}$ edt, Jaypee Brothers, New Delhi, India,p:217-218.

3. AABB Technical Manual, 15 ${ }^{\text {th }}$ edt,2005,P:107-108

4. MAYO CLINIC, Division of Transfusion Medicine, Rochester, Minessota 55905, Blood Donation Consent Form.

5. Eder AF, Hillyer CD, Dy BA, Notari EP, Benjamin RJ. "Adverse Reactions to Allogeneic Whole Blood Donation by 16- and 17-year-olds". Jama 299 (19): 2279-86

6. "Adverse Effect of Blood Donation, Siriraj Experience”. American red cross. Retrieved 200806-01.

7. Eder A, Goldman M, Rossmann S, Waxman D, Bianco C. Selection Criteria to Protect the Blood Donor in North America and Europe: past (dogma), present (evidence), and future (hemovigilance). Transfus med rev. 2009 jul;23(3):205-20.

8. Wiltbank TB, Giordano GF, Kamel H, Tomasulo P, Custer B. Faint and Prefaint Reactions in Whole Blood Donors: An Analysis of Predonation Measurements and Their predictive value. Transfusion. 2008 sep; 48(9):1799-808.

9. Kamel h, tomasulo p, bravo m, wiltbank t, cusick r, james rc, custer b. Delayed adverse reactions to blood donation. Transfusion. 2010 mar; 50(3):556-65. 
10. Eder AF, Dy BA, Kennedy JM, Notari EP, Strupp A, Wissel ME, et al. Haimowitz MD, Newman BH, Chambers LA, Hillyer CD, Benjamin RJ. The American Red Cross Donor Hemovigilance Program: Complications of Blood Donation Reported in 2006. Transfusion. 2008 sep;48(9):1809-19.

11. Newman BH Satz SL, Janowicz NM, Siegfried BA. Donor Reactions in High-School Donors: The Effects of Sex, Weight, and Collection Volume. American Red Cross Blood Services, Southeastern Michigan
Region, Detroit, Michigan 48201, USA. Newmanb@usa.redcross.org

12. Harvey G. Klein, David J. Anstee, Mollison's. Blood Transfusion in Clinical Medicine, $11^{\text {th }}$ edt, 2005, P: $1-12$.

13. Newman BH, Graves S, "A study of 178 consecutive vasovagal syncopal reactions from the prospective of safety." American Red Cross Blood Service, Southeast Region, Detroit, USA. 